\title{
Dose-dense TPF induction chemotherapy for locally advanced head and neck cancer: a phase II study
}

Ching-Yun Hsieh', Ming-Yuh Lein', Shih-Neng Yang ${ }^{2}$, Yao-Ching Wang², Yin-Jun Lin², Chen-Yuan Lin', Chun-Hung Hua ${ }^{3}$, Ming-Hsul Tsai ${ }^{3}$ and Ching-Chan Lin ${ }^{1, *^{*}}$ (i)

\begin{abstract}
Background: Phase 3 studies suggest that induction chemotherapy (ICT) of cisplatin and 5-fluorouracil plus docetaxel (TPF) is effective but toxic for patients with squamous-cell carcinoma of the head and neck (SCCHN). Dose-dense chemotherapy may yield favorable outcomes compared with standard-dose chemotherapy, yet the optimal induction regimen remains undefined. We assessed the efficacy and tolerability of biweekly dose-dense TPF ICT in patients with SCCHN.

Methods: In this prospective phase II study, We enrolled patients with stage III/IV (AJCC 7th edition) unresectable squamous cell carcinoma of head and neck cancer. Patients received dose-dense TPF (ddTPF) with cisplatin and docetaxel $50 \mathrm{mg} / \mathrm{m} 2$ on day 1, leucovorin $250 \mathrm{mg} / \mathrm{m} 2$ on day1, followed by $48-\mathrm{h}$ continuous infusion of $2500 \mathrm{mg} /$ $\mathrm{m} 2$ of 5 -fluorouracil on day 1 and 2, every 2 weeks for 6 cycles followed by radiotherapy. The primary endpoint was the response rate (RR) after ICT.

Results: Fifty-eight patients were enrolled from June 2014 to September 2015. Overall RR after ICT was 89.6\% [complete response (CR), 31\%; partial response (PR), 58.6\%]. Grade 3/4 neutropenia, mucositis, and diarrhea incidences were $25.9,1.7$, and $1.7 \%$, respectively. $94.8 \%$ of patients completed all treatment courses of ICT without dose reduction. The 3-year overall survival (OS) was $54.3 \%$ (95\%Cl: 39.7 to $66.8 \%$ ) and progression-free survival (PFS) was 34.3\% (95\%Cl: 22.0 to 46.9\%). Multivariate analysis showed that CR after ICT is an independent prognostic factor for OS and PFS.
\end{abstract}

Conclusions: Six cycles of ddTPF is an active, well-tolerated induction regimen for patients with SCCHN. The presence of CR after ICT predicted long-term survival.

Trial registration: ClinicalTrials.gov Identifier: NCT04397341, May 21, 2020, retrospectively registered.

Keywords: Head and neck cancer, Docetaxel, Cisplatin, Fluorouracil, Dose-dense chemotherapy, Induction chemotherapy

\footnotetext{
* Correspondence: linchin13256@gmail.com

'Division of Hematology and Oncology, Department of internal medicine,

China Medical University Hospital, China Medical University, 2 Yude Rd, North

District, Taichung 404, Taiwan

${ }^{4}$ Graduate Institute of Biomedical Sciences, China Medical University,

Taichung 404, Taiwan

Full list of author information is available at the end of the article
}

(c) The Author(s). 2020 Open Access This article is licensed under a Creative Commons Attribution 4.0 International License, which permits use, sharing, adaptation, distribution and reproduction in any medium or format, as long as you give appropriate credit to the original author(s) and the source, provide a link to the Creative Commons licence, and indicate if changes were made. The images or other third party material in this article are included in the article's Creative Commons licence, unless indicated otherwise in a credit line to the material. If material is not included in the article's Creative Commons licence and your intended use is not permitted by statutory regulation or exceeds the permitted use, you will need to obtain permission directly from the copyright holder. To view a copy of this licence, visit http://creativecommons.org/licenses/by/4.0/ The Creative Commons Public Domain Dedication waiver (http://creativecommons.org/publicdomain/zero/1.0/) applies to the data made available in this article, unless otherwise stated in a credit line to the data. 


\section{Background}

Chemotherapy combined with radiotherapy (RT) is crucial for patients with locally advanced squamous cell carcinoma of the head and neck (SCCHN) who are inoperable or who require organ preservation. It includes concurrent chemoradiotherapy (CRT) and induction chemotherapy (ICT) followed by RT or CRT $[1,2]$. The most common ICT regimen included cisplatin plus 5-fluorouracil (PF) [3]. However, the PF ICT group was inferior to the CRT group in locoregional control and event-free survival [4]. To improve the efficacy of ICT, a revolutionary treatment strategy in the recent decade has been the addition of docetaxel to PF ICT. Two phase III trials confirmed that TPF ICT provides a significant survival advantage compared with PF ICT $[5,6]$. However, whether TPF ICT plus CRT may also obtain better survival outcomes than the standard CRT is controversial. Two phase III trials showed that TPF ICT plus CRT did not reveal a statistically significant survival benefit compared with CRT alone [7, 8]. Furthermore, only a phase III trial of TPF ICT reached the OS benefit compared with the no-induction group [9]. The most significant clinical concern is the more severe adverse events especially of grade $3 / 4$ neutropenia, and TPF-related deaths, which may compromise treatment efficacy [10].

In the TPF regimen, $75 \mathrm{mg} / \mathrm{m}^{2}$ of docetaxel every 3 weeks is a widespread prescription based on the TAX 323 study [5]. However, the toxicities of triweekly docetaxel have attracted a lot of worries especially for the elderly patients and the Asian population [11, 12]. In a prospective pharmacokinetic study of $75 \mathrm{mg} / \mathrm{m} 2$ docetaxel every 3 weeks for patients with solid tumors, $63 \%$ of elderly patients experienced grade 4 neutropenia compared to $30 \%$ of younger patients [12]. The analysis from published data of phase II and III clinical trials showed that a higher incidence of docetaxel-induced grade 3/4 neutropenia in Asian clinical studies than the non-Asian studies (odds ratio 19.0, [13]). In addition, hematologic toxicity still occurs in these patients even with the reduced dose of triweekly TPF $[14,15]$.

Therefore, although TPF regimen is an effective regimen for patients with SCCHN, the optimal scheduling remains unclear. One of the promising alternatives is the dosedense chemotherapy regimen, which can be reached by the same dose intensity administered at a shorter timeinterval, for instance at a biweekly interval. Dose-dense chemotherapy does not mean greater toxicity. In fact, the experience from the C9741 trial for patients with breast cancer showed that more dose-dense administration was associated with less neutropenia and less need for hospitalization due to febrile neutropenia [16].

In terms of SCCHN, to the best of our knowledge, only one retrospective study reported the biweekly modified TPF chemotherapy was safe and was as effective as triweekly TPF [17]. However, the decreased dose-intensity of cisplatin and docetaxel in this study made the interpretation of the study difficult when compared to the "classical "triweekly TPF regimen. Additionally, the clinical trials in bladder and breast cancers have shown that the benefit of a dose-dense approach in the neoadjuvant setting, but the studies had not been explored in SCCHN [18]. Therefore, we designed a phase II study to evaluate the efficacy and toxicity of the biweekly dose-dense TPF.

\section{Methods \\ Patients}

This prospective single-arm phase II trial enrolled the patients with newly diagnosed locally advanced SCCHN. The study was conducted in accordance with the World Medical Association Declaration of Helsinki (version 2002) and was approved by the China Medical University Hospital Review Board (CMUH103-REC2-038). Patients provided IRB-approved, protocol-specific written informed consent prior to initiating therapy for studyspecific treatment and inclusion in the present study. The study was retrospectively registered in ClinicalTrials.gov (Identifier: NCT04397341).

The inclusion criteria were as follows: (1) histopathologically confirmed diagnosis of AJCC 7th edition stage 3 or 4 unresectable squamous cell carcinoma of the oral cavity, larynx, oropharynx, or hypopharynx; (2) age $>20$ years; (3) ECOG performance status, 0, 1, or 2 at study entry; and (4) adequate organ function. The exclusion criteria were as follows: (1) previous chemotherapy or RT for SCCHN, (2) previous or concurrent malignancy, and (3) peripheral neuropathy $>$ grade 2. Additionally, patients were defined as having an unsuitable condition for radical surgery after the evaluation of a multidisciplinary team. The inoperability criteria included very advanced $\mathrm{T}$ stage (T4b) (tumor invasion into the cervical vertebra, carotid artery, or fixed lymph nodes), risk of significant postoperative dysfunction, and low surgical curability (T3-T4, N2-N3).

\section{Treatment}

Patients received ICT after enrollment. The chemotherapy regimen was delivered with docetaxel $50 \mathrm{mg} / \mathrm{m} 2$ on day 1 , cisplatin $50 \mathrm{mg} / \mathrm{m} 2$ on day 1 and 5 -fluorouracil $2500 \mathrm{mg} / \mathrm{m} 2$ by continuous infusion over $46 \mathrm{~h}$ on Day $1-2$. Moreover, the treatment was administered every 14 days for 6 cycles or until disease progression or intolerant treatment toxicity. In our study, primary G-CSF support was not allowed, but G-CSF administration can be used when the patients had febrile neutropenia or grade 4 neutropenia.

The dose modification was allowed, which was according to the greatest degree of toxicity that was graded by 
NCI-CTCAE Version 4.03. Also, the dose modification of study treatment could be according to the investigator's experiences.

Radiotherapy was administered using the sequential Intensity-Modulated Radiotherapy (IMRT) for 1.8-2.0Gy per fraction with five daily fractions per week for 7 weeks. Two clinical target volumes (CTVs) were designed for risk stratification: CTV1, encompassing the gross tumor volume (GTV) of a primary tumor, metastatic lymph nodes, and regions adjacent to the GTV; and CTV2, encompassing the ipsilateral or contralateral N0 regions at risk of microscopic tumor. During the first course, a dose of 50.4-54.0Gy was included in CTV1 and CTV2. During the second course, a boost of 16.221.6Gy was included in CTV1. The median cumulative dose of 70.2 and 54.0Gy was achieved in CTV1 and CTV2, respectively. Concurrent chemotherapy with weekly cisplatin $35 \mathrm{mg} / \mathrm{m} 2$ was recommended during the period of radiotherapy. However, it is allowed to give radiotherapy alone or substitute cetuximab for cisplatin as the radiosensitizer for the patients not suitable for concurrent chemoradiotherapy by the assessment and discretion of the attending physician. Cetuximab was used at a $250 \mathrm{mg} / \mathrm{m} 2$ on a weekly basis $(400 \mathrm{mg} / \mathrm{m} 2$ as the initial dose) for seven times.

\section{Study design, end point definition, and statistical considerations}

This was a phase II, single-center, prospective clinical trial to evaluate the induction chemotherapy (ICT) with a biweekly dose-dense TPF regimen for SCCNHN patients. The primary endpoint of the study was the response rate (RR) of ICT, while the secondary ones included response rate (RR) of the total treatment, progression-free survival (PFS), overall survival (OS), and toxicity and safety of the treatment. "The response assessment of ICT (the primary endpoint) was performed using CT scan at the end of treatment according to the RECIST 1.1 criteria. Positron emission tomography (PET)/CT scan was also performed to evaluate the response according to the European Organization for Research and Treatment of Cancer (EORTC) 1999 criteria." In addition, only when CT scans failed to reveal an obvious primary, $\mathrm{PET} / \mathrm{CT}$ scan was used to confirm the complete response. The response assessment of the total treatment was performed at 10-12 weeks since the end of radiotherapy with $\mathrm{CT}$ scan, and the response assessment was confirmed by repeat CT scan at an interval of 6-8 weeks. Then, the CT scan was performed every 3-4 months in the first 2 years and every 6-7 months until progression. The PFS was defined as the time from the study registration date to the first day of disease progression at any site or of death by any cause. The OS was defined as the time from the date of study registration to the date of death, or the last confirmed survival date. The toxicity was recorded by the investigators using the National Cancer Institute Common Toxicity Criteria scale version 4.03 (NCI-CTCAE Version 4.03). Toxicities were assessed at each weekly visit during ICT and at the end of treatment.

At the time of study design, the response rate of standard triweekly TPF regimen was reported to be 68 and $72 \%$, respectively $[5,6]$. Therefore, the study was conducted using Simon's optimal two-stage phase II design based on response rate for sample-size calculation. A sample size of 35 patients was required to accept the hypothesis that the true response rate was greater than $90 \%$ with a $90 \%$ power and to reject the hypothesis that the response rate was less than $70 \%$ with $5 \%$ significance. Initially, we planned to enroll 15 patients in the first stage. If 11 or more responses were observed, we planned to continue to the second stage for a total of 35 patients in the analysis. Assuming a dropout rate of $10 \%$, the total number of enrolled patients needed was calculated to be 40. If the endpoints were achieved, we will extend the number of enrolled patients to 60 for translation study. The translational study aims to study the prognostic significance of the metabolic parameters of PET in tumour response to ICT.

Kaplan-Meier survival analysis was used to estimate survival endpoints, and the log-rank test was used to compare the differences between curves. All tests are two-sided, and a $p$-value $<0.05$ was considered to indicate a statistically significant difference. Multivariate analysis was carried out using a Cox proportional hazards regression model. The age was classified into $>50$ and $\leqq 50$ years old using the receiver operating characteristic (ROC) curve.

Statistical analysis was performed with the SPSS software (version 17.0; SPSS, Chicago, IL) and EZR version 1.32. software [19].

\section{Results \\ Patients}

At the first stage of the study, thirteen of 15 patients achieved better than stable disease after ICT treatment. As a consequence, twenty-five patients were further enrolled in the second stage. Overall thirty-five of 40 patients were evaluated to be responders to ICT. The response rate was estimated to be $87.5 \%$. Finally, a total of 60 patients were enrolled in the study from June 2014 to September 2015. Among the 60 patients, only fiftyeight patients were assessable because one patient was excluded because of ineligibility and one withdrew the consent (Fig. 1). The clinical characteristics of the patients were demonstrated in Table 1 . The median follow-up time was 31.8 months (from 1.4 to 43.6 months). The median age is 53 years old (from 28 to 69 
Unresectable stage IV squamous cell carcinoma of head and neck $(\mathrm{N}=60)$

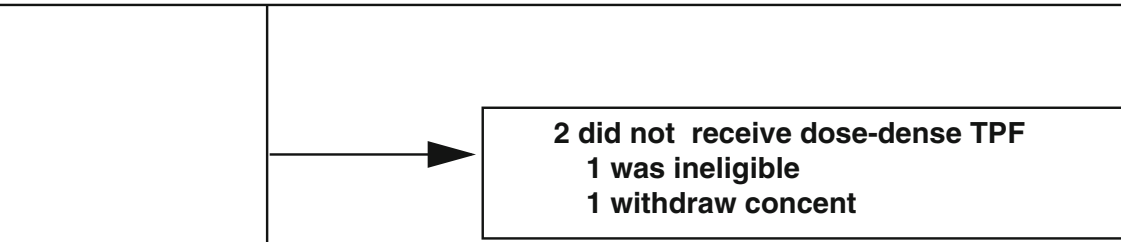

2 refused the following radiotherapy

58 were assigned to receive 6 cycles of dose-dense TPF

3 received $<6$ cycles of treatment

1 had disease progression

2 escaped

55 completed 6 cycles of treatment

56 were evaluable for resonse rates and adeverse effects

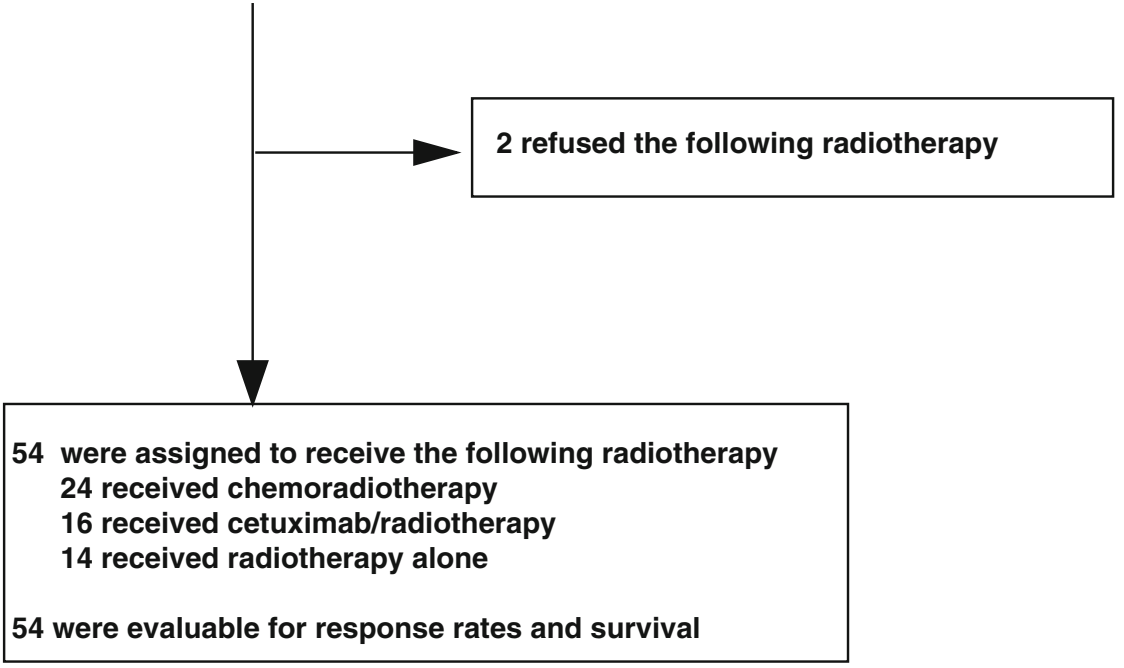

Fig. 1 Enrollment and outcomes

years old). All of them had stage IV SCCHN (IVA, 60.3\%; IVB, 39.7\%, AJCC 7th edition). The primary site of oral cavity/oropharynx/hypopharynx was 31.0\%/ $43.1 \% / 25.9 \%$. Initially, all of the patients were recruited by AJCC 7 th edition, but the stage status was analyzed later according to AJCC 8th edition. Six of 25 (24\%) patients with oropharyngeal cancer (OPC) were considered HPV-associated by the immunohistochemical stain of p16, and 19 (76\%) patients were HPV negative. Most patients reported the history of drinking and smoking.

\section{Efficacy and outcome}

All the 58 patients received ICT with biweekly TPF. Fifty-five of 58 (94.8\%) patients completed all treatment courses of ICT. Three patients did not complete the 6cycle treatment including two who escaped during ICT and the other one had early disease progression. The mean accumulative dose of docetaxel, cisplatin and 5fluorouracil was $288 \mathrm{mg} / \mathrm{m} 2,288 \mathrm{mg} / \mathrm{m} 2$, and 14,474 $\mathrm{mg} / \mathrm{m} 2$, respectively. Therefore, the relative dose intensity was 96,96 and $96.5 \%$, respectively. No dose reduction occurred in all of the patients administered with ICT. Four patients had dose delay of more than 7 days because of infection. The response rates (RR) of ICT was shown in Table 2. On CT scan, 12 of 58 (20.7\%) patients achieved the complete response, but on PET/ CT scan, 18 (31\%) had the metabolic CR (CR). Three patients achieved a stable disease (SD) and 34 patients had a partial response (PR). The overall RR of ICT was $89.7 \%$. All of the patients received full-dose ICT, and none had the reduced dose of docetaxel, cisplatin, or 5-fluorouracil. 
Table 1 Clinical characteristics of the patients

\begin{tabular}{|c|c|c|}
\hline Characteristics $N=58$ & Number & percentage \\
\hline \multicolumn{3}{|c|}{ Age,median (range): 53 (28-69) } \\
\hline$<50$ & 16 & 27.6 \\
\hline $50-65$ & 40 & 69.0 \\
\hline$\geq 65$ & 2 & 3.4 \\
\hline \multicolumn{3}{|l|}{ Gender } \\
\hline Male & 54 & 93.1 \\
\hline Female & 4 & 6.9 \\
\hline \multicolumn{3}{|l|}{ ECOG performance status } \\
\hline 0 & 37 & 63.8 \\
\hline 1 & 21 & 36.2 \\
\hline 2 & 0 & 0 \\
\hline \multicolumn{3}{|l|}{ Smoking } \\
\hline Yes & 49 & 84.5 \\
\hline No & 9 & 15.5 \\
\hline \multicolumn{3}{|l|}{ Alcohol drinking } \\
\hline Yes & 44 & 75.9 \\
\hline No & 14 & 24.1 \\
\hline \multicolumn{3}{|l|}{ Betal nut chewing } \\
\hline Yes & 43 & 74.1 \\
\hline No & 15 & 25.9 \\
\hline \multicolumn{3}{|l|}{ Stage (AJCC 8th edition) } \\
\hline III (HPV+ oropharynx) & 6 & 10.3 \\
\hline IVa & 13 & 22.4 \\
\hline $\mathrm{IVb}$ & 39 & 67.3 \\
\hline \multicolumn{3}{|l|}{$\mathrm{T}$} \\
\hline 1,2 & 13 & 22.4 \\
\hline 3 & 9 & 15.5 \\
\hline $4 a$ & 13 & 22.4 \\
\hline $4 b$ & 23 & 39.7 \\
\hline \multicolumn{3}{|l|}{ N } \\
\hline 0 & 5 & 8.6 \\
\hline 2 (HPV+ oropharynx) & 3 & 5.2 \\
\hline $2 b$ & 14 & 24.1 \\
\hline $2 c$ & 11 & 19.0 \\
\hline 3 & 25 & 43.1 \\
\hline \multicolumn{3}{|l|}{ Site } \\
\hline Oral cavity & 18 & 31.0 \\
\hline Oropharynx & 25 & 43.1 \\
\hline HPV associated & 6 & 10.4 \\
\hline HPV negative & 19 & 32.7 \\
\hline Hypopharynx & 15 & 25.9 \\
\hline \multicolumn{3}{|l|}{ Neck dissection after ICT } \\
\hline Yes & 8 & 13.8 \\
\hline No & 50 & 86.2 \\
\hline
\end{tabular}

Table 2 Response to induction chemotherapy and to total treatment of induction therapy plus radiotherapy

\begin{tabular}{lcl}
\hline & Number & Percentage \\
\hline Response of Induction chemotherapy $(N=58)$ & \\
Overall RR & 52 & $89.7 \%$ \\
CR & 18 & $31.0 \%$ \\
PR & 34 & $58.6 \%$ \\
SD & 3 & $5.2 \%$ \\
PD & 3 & $5.2 \%$ \\
Response of ICT plus RT $(N=54)$ & \\
Overall RR & 42 & $77.8 \%$ \\
CR & 37 & $68.5 \%$ \\
PR & 5 & $9.3 \%$ \\
SD & 6 & $11.1 \%$ \\
PD & 6 & $11.1 \%$ \\
\hline
\end{tabular}

$C R$ complete response, ICT induction chemotherapy, $P R$ partial response, $P D$ progressive disease, $R R$ response rate, $R T$ radiotherapy, $S D$ stable disease

After ICT, 2 patients refused the following radiotherapy. Twenty-four patients received chemoradiotherapy, 16 patients received cetuximab/RT, and 14 patients received RT alone. Therefore, a total of 54 patients is evaluable for treatment response after radiotherapy. Three of 54 (5.5\%) cannot complete the RT program because that one patient had severe pneumonia, another developed ischemic stroke during the treatment, and one escaped from the treatment protocol. After the CRT or RT process, 37 (68.5\%) patients achieved CR, 5 (9.3\%) had a PR, 6 (11.1\%) had a stable disease, and 6 (11.1\%) had disease progression. The overall RR of the total treatment was $77.8 \%$.

The 3-year OS and PFS were 56.3\% $(95 \% \mathrm{CI}, 41.6-$ $68.6 \%)$ and $34.3 \%$, (95\%CI, 22.0-46.9\%), respectively, as seen in Fig. 2a and b. The 3-year local-recurrence free survival was $48.4 \%$ (95\%CI, 34.1-46.9\%) and the 3-year metastasis free-survival was $85.6 \%$ (95\%CI, 71.9-93.0\%), as seen in Fig. 2c and d.

We also analyzed the association between tumour response (RR) of ICT and the survival outcomes of the patients. The Kaplan-Meier analysis showed that the patients with complete response had superior survival to those with partial response and nonresponders. The 3year OS and PFS were $81.7 \%$ (95\%CI, 53.1-93.8\%) and $59.3 \%(95 \% \mathrm{CI}, 33.0-78.1 \%)$ in patients with complete response $(p$ value $<0.001)$ and $45.9 \%(95 \%$ CI,27.4-62.6\%) and $25.5 \%(95 \% \mathrm{CI}, 11.9-41.4 \%)$ in patients with partial response ( $p$ value $<0.001$ ), respectively, as seen in Fig. 3 . All patients with the response less than PR passed away within 20 months. We also performed the multivariate analysis to consider other variables, including age, stage, primary site, and smoking status. We did not include HPV status in Cox regression analysis because only 6 

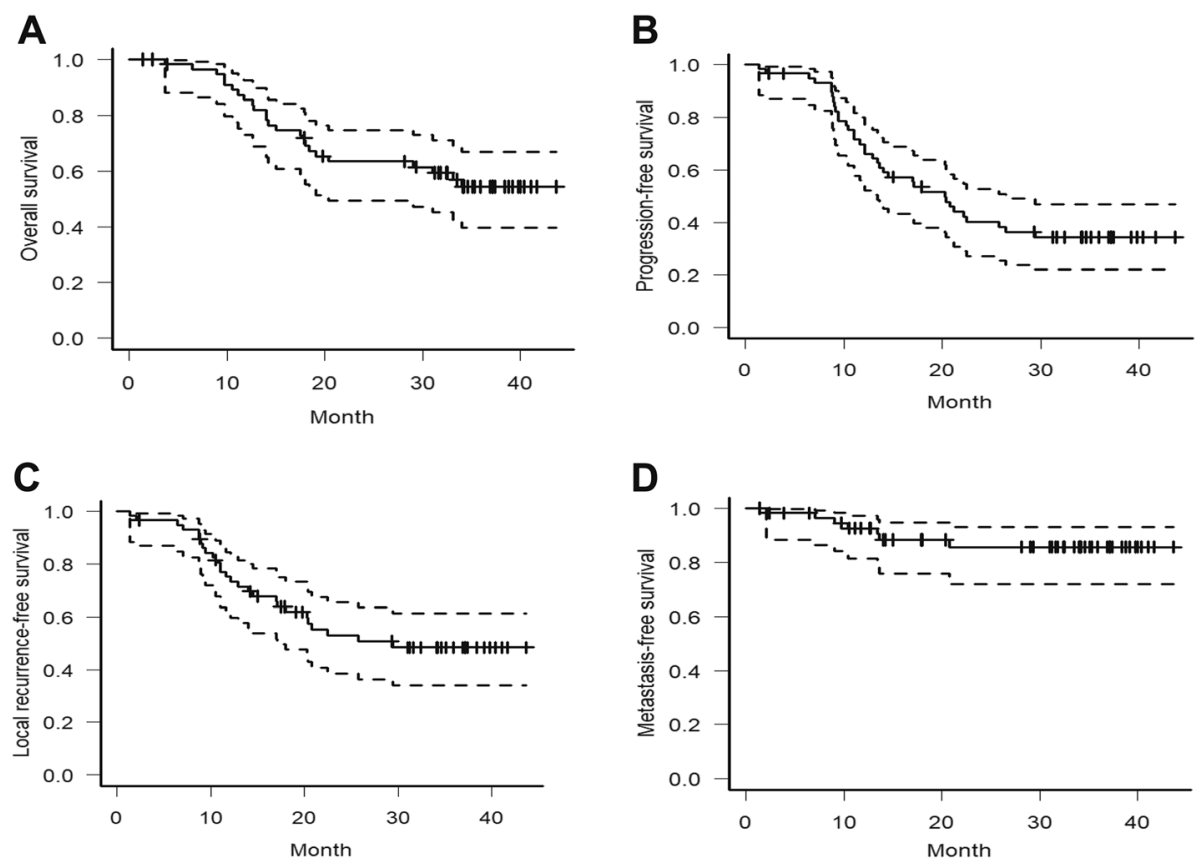

Fig. 2 Survival analsysis. a Overall survival. b Progression-free survival. c Local recurrence-free survival. d Metastasis-free survival

patients were HPV-associated. The results showed that response status after ICT was the only significant prognostic factor for OS and PFS (Table S1).

\section{Treatment-related adverse events}

The treatment-related adverse events during ICT are shown in Table 3. During this, mucositis was the most common event $(33 / 58,56.9 \%)$, but only one patient suffered from grade 3 mucositis. In grade $3 / 4$ adverse events, 15 patients (25.9\%) had neutropenia, and 6 (10.3\%) developed febrile neutropenia. Also, 11 patients developed infection; however, no patients died during the process.

\section{Discussion}

Our study showed that biweekly dose-dense TPF ICT in locally advanced SCCHN had a promising treatment response. The overall response rate and complete response rate were 89.7 and $31 \%$, respectively. The 3 -year OS and PFS were 56.3 and $34.3 \%$, respectively. Compared to the data from TAX323 and TAX324 trials, standard triweekly TPF ICT regimen achieved 68 and $72 \%$ postinduction RR, respectively $[5,6]$. The 3 -year OS and PFS for patients in TAX 323 were 37 and $17 \%$, and those in TAX 324 were 62.0 and $49.0 \%$, respectively $[5,6]$. Particularly, $25.9 \%$ of the grade 3-4 neutropenia in our study is markedly lower than previously reported. For example, TAX323 trial reported $76.9 \%$ of the grade $3-4$
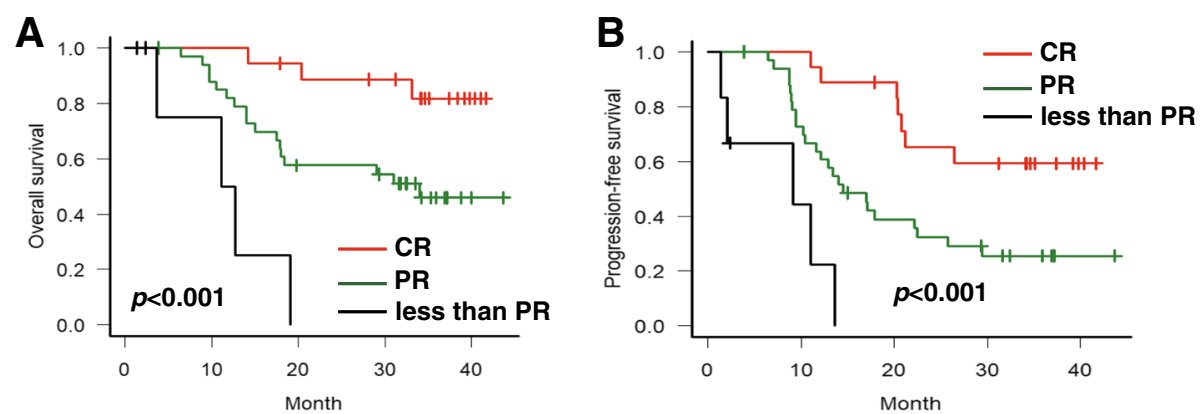

Fig. 3 Survival analysis stratified by response rate (RR) of ICT. a Overall survival. b Progression-free survival. CR: complete response; PR: partial response. ICT: induction chemotherapy 
Table 3 Adverse effects of treatment

\begin{tabular}{lll}
\hline NICIC CTG grade & Grade 1,2 & Grade 3,4 \\
\hline During induction chemotherapy $(n=58)$ & $1(1.72 \%)$ \\
anemia & $5(13.79 \%)$ & $15(25.86 \%)$ \\
neutropenia & $5(13.79 \%)$ & 0 \\
thrombocytopenia & 0 & $58(100 \%)$ \\
alopecia & 0 & 0 \\
Weight loss & $3(5.17 \%)$ & 0 \\
Hand foot syndrome & $28(48.27 \%)$ & $1(1.72 \%)$ \\
Mucositis/stomatitis & $33(56.89 \%)$ & $6(10.34 \%)$ \\
Febrile neutropenia & 0 & 0 \\
Acute kidney injury & $17(29.31 \%)$ & $18(31.03 \%)$ \\
Hyponatremia & $19(32.75 \%)$ & $5(13.79 \%)$ \\
Hypokalemia & $20(34.48 \%)$ & 0 \\
nausea & $12(20.68 \%)$ & 0 \\
vomiting & $1(1.72 \%)$ & $1(1.72 \%)$ \\
Diarrhea & $10(17.24 \%)$ & 0 \\
Hearing loss & $10(17.24 \%)$ & $1(1.72 \%)$ \\
Lethargy & $4(6.89 \%)$ & 0 \\
Peripheral neuropathy & $29(50.00 \%)$ & \\
\hline
\end{tabular}

neutropenia, and TAX324 trial reported $83 \%$ of the grade 3-4 neutropenia [5, 6].

Toxicity is a major issue of ICT, with up to $6 \%$ toxic deaths and $11 \%$ of febrile neutropenia $[4,20]$. Some studies had tried to find fewer toxic regimens by reducing chemotherapy dose $[21,22]$. HM. Wang et al. reduced the dose to $90 \%$ of the original TPF dosage (docetaxel $67.5 \mathrm{mg} / \mathrm{m} 2$ on Day 1 , cisplatin $67.5 \mathrm{mg} / \mathrm{m} 2$ on Day 1 and $5 \mathrm{FU} 675 \mathrm{mg} / \mathrm{m} 2$ on Day $1-5)$ as the induction treatment. The grade 3-4 neutropenia was $35 \%$, and the overall response rate was $73.1 \%$ after induction therapy [21]. A retrospective study from J Fayette et al. in France used the modified TPF regimen of docetaxel and cisplatin at $40 \mathrm{mg} / 2$ on day 1 and a bolus of $5 \mathrm{FU}$ at $400 \mathrm{mg} / \mathrm{m} 2$, then $1000 \mathrm{mg} / \mathrm{m} 2$ on Day $1-2$ every 2 weeks. The authors reported $10 \%$ of febrile neutropenia, $83 \%$ of overall response rate and $19 \%$ of complete response [22]. Notably, the regimen adopted by J Fayette et al. was similar to that our study used, such as biweekly administration, and 48-h infusion of high-dose 5FU. Biweekly administration of docetaxel might be better tolerated due to the reduced peak drug concentrations [23]. Data from colon cancer and gastric cancer had shown that biweekly $48 \mathrm{~h}$ infusion of $5 \mathrm{FU}$ can increase the response rate with fewer side effects of myelotoxicity [24, 25]. However, the inherent bias of the retrospective study, the heterogenous post-ICT treatment (including surgery and radiotherapy) and the reduced dose intensity of cisplatin and docetaxel compared to the standard TPF regimen made the interpretation of the results difficult.

Dose-Dense Chemotherapy aims to achieve maximum tumor kill by shortening the interval of chemotherapy delivery. Several clinical trials and metastasis from breast cancer, bladder cancer, and lymphoma had revealed that dose-dense regimen improved response rate and survival outcomes [26, 27]. However, the associated studies in head and neck cancer are scarce. Our TPF regimen included $50,50,2500$, and $250 \mathrm{mg} / \mathrm{m}^{2}$ of docetaxel, cisplatin, 5-fluorouracil, and leucovorin, respectively. We maintained the average dose intensity of the traditional TPF, with less toxicity than triweekly TPF and similar rates of neutropenia (25.86\%) compared with the weekly TPF regimen. Additionally, 94.8\% of patients completed 6 cycles of treatment without dose reduction. The high rate of treatment completion may explain the better response rate and survival outcomes in our study.

ICT also was a predictor of survival for locally advanced SCCHN. A recent meta-analysis study showed the ICT responders had better survival than nonresponders [28]. Moreover, a phase II study demonstrated that responders after one cycle of split-dose TPF ICT were a survival predictor for oral and oropharyngeal squamous cell carcinoma (OPSCC) [29]. A review article that recruited seven studies displayed that the standardized uptake value (SUV) reduction in interim PET scan may predict ICT response, PFS, and OS [30]. In our study, biweekly TPF ICT demonstrated around 90\% RR and a high $\mathrm{CR}$ rate (31.0\%). Also, the patients with CR had better OS and PFS than those with non-CR. Accordingly, patients with metabolic non-CR may need an additional treatment after ICT.

Limitations of our study include the lack of a comparator group and the relatively small sample size. Although the primary objective of this study is to investigate the response rate of ICT, the heterogeneous treatment during radiotherapy could have introduced major biases in the analysis of OS. Additionally, 14 of 54 (25.9\%) patients could receive radiotherapy only, which raised the concern that the administration of ICT may compromise the completion of subsequent concomitant administration of chemotherapy or biotherapy. To draw definitive conclusions is difficult in this regard because compliance and toxicity data are differently reported. However, according to the Spanish TTCC trial, which used standard triweekly TPF regimen followed by concomitant CRT regimen, $30 \%$ of patients would never receive radiotherapy, $41 \%$ of patients needed dose reduction, and $17 \%$ of patients discontinued CRT treatment [7]. In our study, 4/58 (6.9\%) patients did not receive the following radiotherapy, and 3/54 (5.6\%) patient discontinued CRT treatment. The relative tolerability of the dose-dense TPF regimen may be attributed to fewer 
grade 3-4 adverse effects and shortened treatment duration. Additionally, because radiotherapy would follow the induction chemotherapy within 4 weeks, it is impossible to confirm our treatment response by repeat assessments that should be performed no less than 4 weeks after the RECIST criteria for the response classification was initially met. Finally, our study design is unlikely to answer the question of whether the combination of dose-dense induction therapy plus the following radiotherapy can beat conventional concomitant CRT therapy.

\section{Conclusions}

In conclusion, the investigational regimen of biweekly TPF ICT appears to have favourable tolerability with an acceptable response rate compared to published studies. This regimen had fewer grade 3/4 hematologic adverse events including neutropenia, anemia, and thrombocytopenia than the triweekly TPF. Also, the survival figures were not inferior to the reported studies of triweekly TPF ICT. The patients with CR after ICT had superior survival outcomes than those with non-CR. Thus, future studies should focus on whether further treatments are necessary for patients with non-CR after ICT.

\section{Supplementary information}

Supplementary information accompanies this paper at https://doi.org/10. 1186/s12885-020-07347-6.

Additional file 1: Table S1. Multivariate analysis of overall survival and progression-free survival.

\section{Abbreviations \\ Cl: Confidence interval; CR: Complete response; CRT: Chemoradiotherapy; CTVs: Clinical target volumes; ddTPF: Dose-dense TPF; EORTC: European Organization for Research and Treatment of Cancer; GTV: Gross tumor volume; HPV: Human papilloma virus; ICT: Induction chemotherapy; IMRT: Intensity-Modulated Radiotherapy; OS: Overall survival; PET: Positron emission tomography; PF: Cisplatin plus 5-fluorouracil; PFS: Progression-free survival; PR: Partial response; ROC: Receiver operating characteristic; RR: Response rate; RT: Radiotherapy; SCCHN: Squamous-cell carcinoma of the head and neck; SD: Stable disease; TPF: Cisplatin and 5-fluorouracil plus docetaxel}

\section{Acknowledgments \\ Not applicable}

\section{Authors' contributions}

All authors contributed to the study conception and design. Material preparation, data collection and analysis were performed by MYL, SNYang, $Y C W, Y J L, C Y L, C H H$, and MHT. The first draft of the manuscript was written by $\mathrm{CCL}_{\text {, }}$ and $\mathrm{CYH}$ and all authors commented on previous versions of the manuscript. All authors read and approved the final manuscript.

\section{Funding}

This work was supported by the National Health Research Institutes [NHRI180A1- CACO-13191902]; and China Medical University [DMR-108-BC-6]. The funders had no role in study design, data collection and analysis, decision to publish, or preparation of the manuscript.

\section{Availability of data and materials}

The datasets generated and analyzed in the current study are available from the corresponding author upon reasonable request.

\section{Ethics approval and consent to participate}

The study was conducted in accordance with the World Medical Association Declaration of Helsinki (version 2002) and was approved by the China Medical University Hospital Review Board (CMUH103-REC2-038).

Patients provided IRB-approved, protocol-specific written informed consent prior to initiating therapy for study-specific treatment and inclusion in the present study.

\section{Consent for publication}

Patients signed informed consent regarding publishing their data and photographs.

\section{Competing interests}

The Authors declare that there is no conflict of interest.

\section{Author details}

'Division of Hematology and Oncology, Department of internal medicine, China Medical University Hospital, China Medical University, 2 Yude Rd, North District, Taichung 404, Taiwan. ${ }^{2}$ Division of Radiation Oncology, China Medical University Hospital, China Medical University, Taichung 404, Taiwan. ${ }^{3}$ Department of Otorhinolaryngology, China Medical University Hospital, China Medical University, Taichung 404, Taiwan. ${ }^{4}$ Graduate Institute of Biomedical Sciences, China Medical University, Taichung 404, Taiwan.

Received: 21 June 2020 Accepted: 26 August 2020

Published online: 01 September 2020

\section{References}

1. Gregoire V, Lefebvre JL, Licitra L, Felip E. Squamous cell carcinoma of the head and neck: EHNS-ESMO-ESTRO clinical practice guidelines for diagnosis, treatment and follow-up. Ann Oncol. 2010;21(Suppl 5):v184-6. https://doi. org/10.1093/annonc/mdq185.

2. Marur S, Forastiere AA. Head and neck squamous cell carcinoma: update on epidemiology, diagnosis, and treatment. Mayo Clin Proc. 2016;91(3):386-96. https://doi.org/10.1016/j.mayocp.2015.12.017.

3. Pignon JP, le Maitre A, Maillard E, Bourhis J. Meta-analysis of chemotherapy in head and neck cancer (MACH-NC): an update on 93 randomised trials and 17,346 patients. Radiother Oncol. 2009;92(1):4-14. https://doi.org/10. 1016/j.radonc.2009.04.014.

4. Forastiere AA, Zhang Q, Weber RS, Maor MH, Goepfert H, Pajak TF, et al. Long-term results of RTOG 91-11: a comparison of three nonsurgical treatment strategies to preserve the larynx in patients with locally advanced larynx cancer. J Clin Oncol. 2013;31(7):845-52. https://doi.org/10.1200/jco. 2012.43.6097.

5. Vermorken JB, Remenar E, van Herpen C, Gorlia T, Mesia R, Degardin M, et al. Cisplatin, fluorouracil, and docetaxel in unresectable head and neck cancer. N Engl J Med. 2007;357(17):1695-704. https://doi.org/10.1056/ NEJMoa071028.

6. Posner MR, Hershock DM, Blajman CR, Mickiewicz E, Winquist E, Gorbounova $V$, et al. Cisplatin and fluorouracil alone or with docetaxel in head and neck cancer. N Engl J Med. 2007;357(17):1705-15. https://doi.org/ 10.1056/NEJMoa070956.

7. Hitt R, Grau JJ, Lopez-Pousa A, Berrocal A, Garcia-Giron C, Irigoyen A, et al. A randomized phase III trial comparing induction chemotherapy followed by chemoradiotherapy versus chemoradiotherapy alone as treatment of unresectable head and neck cancer. Ann Oncol. 2014;25(1):216-25. https:// doi.org/10.1093/annonc/mdt461.

8. Cohen EE, Karrison TG, Kocherginsky M, Mueller J, Egan R, Huang CH, et al. Phase III randomized trial of induction chemotherapy in patients with N2 or N3 locally advanced head and neck cancer. J Clin Oncol. 2014;32(25):273543. https://doi.org/10.1200/jco.2013.54.6309.

9. Ghi MG, Paccagnella A, Ferrari D, Foa P, Alterio D, Codeca C, et al. Induction TPF followed by concomitant treatment versus concomitant treatment alone in locally advanced head and neck cancer. A phase II-III trial. Ann Oncol. 2017;28(9):2206-12. https://doi.org/10.1093/annonc/mdx299.

10. Haddad RI, Posner M, Hitt R, Cohen EEW, Schulten J, Lefebvre JL, et al. Induction chemotherapy in locally advanced squamous cell carcinoma of the head and neck: role, controversy, and future directions. Ann Oncol. 2018;29(5):1130-40. https://doi.org/10.1093/annonc/mdy102. 
11. Kenmotsu H, Tanigawara Y. Pharmacokinetics, dynamics and toxicity of docetaxel: why the Japanese dose differs from the Western dose. Cancer Sci. 2015;106(5):497-504. https://doi.org/10.1111/cas.12647.

12. ten Tije AJ, Verweij J, Carducci MA, Graveland W, Rogers T, Pronk T, et al. Prospective evaluation of the pharmacokinetics and toxicity profile of docetaxel in the elderly. J Clin Oncol. 2005;23(6):1070-7. https://doi.org/10 1200/jco.2005.03.082

13. Yano R, Konno A, Watanabe K, Tsukamoto H, Kayano Y, Ohnaka H, et al. Pharmacoethnicity of docetaxel-induced severe neutropenia: integrated analysis of published phase II and III trials. Int J Clin Oncol. 2013;18(1):96104. https://doi.org/10.1007/s10147-011-0349-5.

14. Ahn JS, Cho SH, Kim OK, Lee JK, Yang DH, Kim YK, et al. The efficacy of an induction chemotherapy combination with docetaxel, cisplatin, and 5-FU followed by concurrent chemoradiotherapy in advanced head and neck cancer. Cancer Res Treat. 2007;39(3):93-8. https://doi.org/10.4143/crt.2007.39. 3.93.

15. Okano S, Enokida T, Onoe T, Ota Y, Motegi A, Zenda S, et al. Induction TPF chemotherapy followed by CRT with fractionated administration of cisplatin in patients with unresectable locally advanced head and neck cancer. Int J Clin Oncol. 2019;24(7):789-97. https://doi.org/10.1007/s10147-019-01418-w.

16. Citron ML, Berry DA, Cirrincione C, Hudis C, Winer EP, Gradishar WJ, et al. Randomized trial of dose-dense versus conventionally scheduled and sequential versus concurrent combination chemotherapy as postoperative adjuvant treatment of node-positive primary breast cancer: first report of intergroup trial C9741/Cancer and leukemia group B trial 9741. J Clin Oncol. 2003;21(8):1431-9. https://doi.org/10.1200/jco.2003.09.081.

17. Demirci NS, Aksoy S, Özdemir NY, Erdem GU, Ozcelik M, Tanrikulu E, et al. Modified docetaxel, cisplatin and fluorouracil therapy as the first-line treatment for patients with recurrent/metastatic squamous cell carcinoma of the head and neck cancer: a retrospective study. Curr Med Res Opin. 2017;33(3):401-7. https://doi.org/10.1080/03007995.2016.1257984.

18. Iyer G, Balar AV, Milowsky MI, Bochner BH, Dalbagni G, Donat SM, et al. Multicenter prospective phase II trial of Neoadjuvant dose-dense gemcitabine plus Cisplatin in patients with muscle-invasive bladder Cancer. J Clin Oncol. 2018;36(19):1949-56. https://doi.org/10.1200/jco.2017.75.0158.

19. Kanda Y. Investigation of the freely available easy-to-use software 'EZR' for medical statistics. Bone Marrow Transplant. 2013;48(3):452-8. https://doi.org/ 10.1038/bmt.2012.244

20. Haddad R, O'Neill A, Rabinowits G, Tishler R, Khuri F, Adkins D, et al. Induction chemotherapy followed by concurrent chemoradiotherapy (sequential chemoradiotherapy) versus concurrent chemoradiotherapy alone in locally advanced head and neck cancer (PARADIGM): a randomised phase 3 trial. Lancet Oncol. 2013;14(3):257-64. https://doi.org/10.1016/ s1470-2045(13)70011-1.

21. Wang HM, Lin $\mathrm{CY}$, Hsieh $\mathrm{CH}$, Hsu CL, Fan $\mathrm{KH}$, Chang JT, et al. Induction chemotherapy with dose-modified docetaxel, cisplatin, and 5-fluorouracil in Asian patients with borderline resectable or unresectable head and neck cancer. J Formos Med Assoc. 2017;116(3):185-92. https://doi.org/10.1016/j. jfma.2016.03.005

22. Fayette J, Fontaine-Delaruelle C, Ambrun A, Daveau C, Poupart M, Ramade A, et al. Neoadjuvant modified TPF (docetaxel, cisplatin, fluorouracil) for patients unfit to standard TPF in locally advanced head and neck squamous cell carcinoma: a study of 48 patients. Oncotarget. 2016;7(24):37297-304 https://doi.org/10.18632/oncotarget.8934.

23. Hervonen $P$, Joensuu $H$, Joensuu T, Ginman C, McDermott R, Harmenberg $U$, et al. Biweekly docetaxel is better tolerated than conventional threeweekly dosing for advanced hormone-refractory prostate cancer. Anticancer Res. 2012:32(3):953-6.

24. Beerblock K, Rinaldi Y, André T, Louvet C, Raymond E, Tournigand C, et al. Bimonthly high dose leucovorin and 5-fluorouracil 48-hour continuous infusion in patients with advanced colorectal carcinoma. Groupe d'Etude et de Recherche sur les cancers de I'Ovaire et Digestifs (GERCOD). Cancer. 1997;79(6):1100-5.

25. Yeh $\mathrm{KH}$, Yeh $\mathrm{SH}, \mathrm{Hsu} \mathrm{CH}$, Wang TM, Ma IF, Cheng AL. Prolonged and enhanced suppression of thymidylate synthase by weekly 24-h infusion of high-dose 5-fluorouracil. Br J Cancer. 2000;83(11):1510-5. https://doi.org/10. 1054/bjoc.2000.1456.

26. Reinisch M, Ataseven B, Kümmel S. Neoadjuvant dose-dense and doseintensified chemotherapy in breast Cancer - review of the literature. Breast Care (Basel). 2016;11(1):13-20. https://doi.org/10.1159/000444543.
27. Lyman GH, Barron RL, Natoli JL, Miller RM. Systematic review of efficacy of dose-dense versus non-dose-dense chemotherapy in breast cancer, nonHodgkin lymphoma, and non-small cell lung cancer. Crit Rev Oncol Hematol. 2012;81(3):296-308. https://doi.org/10.1016/j.critrevonc.2011.04.010.

28. Kiong KL, de Souza NN, Sultana R, lyer NG. Meta-analysis of induction chemotherapy as a selection marker for chemoradiation in the head and neck. Laryngoscope. 2018;128(7):1594-601. https://doi.org/10.1002/lary. 27011.

29. Inhestern J, Schmalenberg H, Dietz A, Rotter N, Maschmeyer G, Jungehulsing $M$, et al. A two-arm multicenter phase II trial of one cycle chemoselection split-dose docetaxel, cisplatin and 5-fluorouracil (TPF) induction chemotherapy before two cycles of split TPF followed by curative surgery combined with postoperative radiotherapy in patients with locally advanced oral and oropharyngeal squamous cell cancer (TISOC-1). Ann Oncol. 2017:28(8):1917-22. https://doi.org/10.1093/annonc/mdx202.

30. Dos Anjos RF, Dos Anjos DA, Vieira DL, Leite AF, Figueiredo PT, de Melo NS. Effectiveness of FDG-PET/CT for evaluating early response to induction chemotherapy in head and neck squamous cell carcinoma: a systematic review. Medicine (Baltimore). 2016;95(32):e4450. https://doi.org/10.1097/md. 0000000000004450

\section{Publisher's Note}

Springer Nature remains neutral with regard to jurisdictional claims in published maps and institutional affiliations.

\section{Ready to submit your research? Choose BMC and benefit from:}

- fast, convenient online submission

- thorough peer review by experienced researchers in your field

- rapid publication on acceptance

- support for research data, including large and complex data types

- gold Open Access which fosters wider collaboration and increased citations

- maximum visibility for your research: over $100 \mathrm{M}$ website views per year

At BMC, research is always in progress.

Learn more biomedcentral.com/submissions 